\title{
乳酸菌飲科の連続投与と唃蝕との 相関性に関する研究
}

\author{
その 1 ヤルト菌の口腔内定着性の有無に関する研究
}

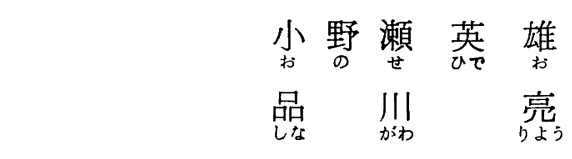

日本大学大学院歯学研究科学生細菌学専攻（指導：白土寿一教授）

\section{I. 緒 論}

近年乳酸菌飲料の連続投与が予防医学的, 栄養学的に 好結果をおよぼすことが注目されている。代田はすでに 約三十年前より乳酸菌研究を行ない予防医学的見地より 乳酸菌飲料ヤクルトを創製した ${ }^{1)}$ 。

その後, このヤクルト菌に関するいろいろの実験が進 むにつれて, ヤクルト菌は試験動物に連続投与されるこ とにより，その動物腸内に acidophilus flora (bifidus flora $)^{2)}$ を形成して, 他菌群の増殖を阻止し 3 腸内外来性 病原菌の感染, 大腸菌群の異常醱酵等を防止し, Vita$\min B$ 群の合成を促進することなどが判明した。さらに この他に体重増加作用 ${ }^{5) 6)}$ ，腸内における腐敗機転の抑 制作用のあること7〕報告されている。

しかしながら，他方では，この乳酸桿菌は人の口腔二 大疾患の一つである歯牙唃蝕症の原因菌または誘因菌と して数十年来疑を受け，末だ解決されていないのが現状 である ${ }^{8) 99}$

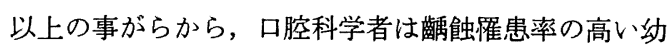
児, 児童にいわゆる乳酸菌飲料を連続投与寸ることに対 して, ある種の疑問を抱くものである。

そこで著者は乳酸菌飲料である「ヤクルト」を長期間 飲料することによつて，その中に含有されている「ヤク ルト菌」(乳酸桿菌の一種)が鹋蝕発症の原因または遠因 となりうるものであるかどらかを解明することは，口腔 病の疫学的立場から非常に重要な課題であると考え, こ の問題を究明しょうとした。

今回は先ず始めの手がかりとして「ヤクルト」を飲料 させることによつて, ヤクルト菌が実験動物ラット口腔 内に定着するものであるかどらかを追求したのでこれま での成績をここに述べる。

\section{II. 実験方法}

1. 供試菌株

「クロレラヤクルト」より分離した「ヤクルト菌」の Streptomycin 耐性株を使用した。SM 耐性株の作り方は 固型培地法を用い $100 \mathrm{mg} / \mathrm{ml} の \mathrm{SM}$ 耐性を獲得せしめ た。

供試菌株の性状 ${ }^{13)}$

ヤクルト菌は $0.6 \sim 0.7 \times 1.5 \sim 5.0 \mu$ のグラム陽性で, 芽胞なく塩基性色素によく染る。培養は通性嫌気性で, 糖加培地に生育し，とくにベジタブルジュースを好む。 平板培地上の集落形成はトマトジュース寒天培地, GYB 寒天培地上にて, 上く生育し, $\mathrm{BCP}$ 加プレートカウン 卜寒天培地, 並びに普通寒天, 標準寒天培地等の単純培 地上にては極度に悪く生育をする（コロニー発育悪く， ピンポイントコロニー形成)。トマトジュース 寒天, GYB 寒天培地上にて白色または類白色, 円板状または 扁平，紡錘状のコロニーを作り， $\mathrm{GYB}$ 寒天上の $\mathrm{CaCO}_{3}$ の溶解リングは明膫である。著者等が実験に使用したヤ クルト菌の性状もまつたく上記の性状と同一であること を確認した。

各種糖醈酵性は表 1 亿示すとおりである。

2. 被験動物

Wister 系 albino rat 27 兀 (今15, 우12) は生後三週 間のものを使用した。

3. 供試菌の投与方法

投与菌液

SM 而性ヤクルト菌を Rogosa's S. L. broth ${ }^{10)}$ に 24 時間培養の後, $1200 \mathrm{G}, 30$ 分の遠心力で遠心沈涮し菌体 を集収, これを生理食塩水をもつて洗滌し，再遠沈して 集収した菌を生理食塩水に浮遊せしめた。その時の菌数 
表 1 ヤクルト菌の各種糖醊酵性

\begin{tabular}{|c|c|c|c|c|c|c|c|c|c|c|c|c|c|c|}
\hline 糖 & $\mathrm{Gr}$ & $\mathrm{Ga}$ & A & TA & 種 & $\mathrm{Gr}$ & $\mathrm{Ga}$ & A & $\mathrm{TA}$ & 糖 & $\mathrm{Gr}$ & $\mathrm{Ga}$ & A & TA \\
\hline Glucose & + & - & + & 0.14 & Trehalose & + & - & + & 0.20 & Mannitol & + & - & - & \\
\hline Fructose & + & - & + & 0.13 & Dextrin & + & - & + & 0.15 & Sorbitol & + & - & & \\
\hline Mannose & + & - & + & 0.25 & Starch & + & - & + & 0.28 & Inulin & + & - & & \\
\hline Galactose & + & - & + & 0.20 & Melibiose & + & - & - & & $\alpha$-Methylgluc & + & - & & \\
\hline Maltose & + & - & - & 0.24 & xylose & + & - & - & & Arbutin & + & - & \pm & \\
\hline Sucrose & + & - & - & & Arabinose & + & - & - & & Salicin & + & - & \pm & \\
\hline Lactose & + & - & \pm & 0.05 & Rhamnose & + & - & - & & Nosugar & + & - & - & \\
\hline Raffinose & + & - & - & & Glycerol & + & - & - & & (Control) & & & & \\
\hline
\end{tabular}

は $11 \times 10^{7} / \mathrm{ml}$ であつた。

投与方法

投与菌浮遊液 $0.5 \mathrm{ml}$ を水銃をもつて 午前 9 時にラッ ト口腔内に注入した。これを一回の投与量とした。この 投与を一日一回のみ行なつたものをA群, 一日一回, 三 日間連続投与を行なつたものを B 群, 一日一回, 5 日間 連続投与を行なつたものを C 群として, 各群ともラット 9 匹（今 5, ㅇ 4 匹）を使用した。菌の投与終了後, 時 間の経過とともに投与菌の口腔内消長を追跡した。追跡 のための検査は初日は三回すなわち二時間後, 四時間後 八時間後に行なつた。その後は一日一回午前九時に行な つた。

\section{4. 唾液の採取方法}

白土の考案した有頭均子状ガラス棒を煮沸隇菌し, ラ ットの上下唇を $70 \%$ アルコールで清拭の後, 舌下部渚留 唾液によつて污染させ唾液を採取した。

採取唾液は直ちに滅菌ペプトン水中にて洗滌し，よく 混和した後, その $0.05 \mathrm{ml}$ を $\mathrm{SM} 100 \mathrm{mg} / \mathrm{ml}$ 加 Rogosa's S. L. medium に表面塗布し, Rogosa's S. L. medium は $37^{\circ} \mathrm{C}, 72$ 時間, 血液寒天は $37^{\circ} \mathrm{C} 48$ 時間培養し, そ こに生じた集落数をもつて菌数を計算し, 総菌数に対す る投与ヤクルト菌の出現比率を算出した.

\section{III. 実験成績}

生後三週間後のラットロ腔に SM $100 \mathrm{mg} / \mathrm{ml}$ 耐性ヤク ルト菌を投与し，投与菌のラット口腔内に打ける定着性 の有無を観察した。その成績は表 3，4，5 である。

投与前の各ラットの口腔内には勿論 SM 耐性 Lactobacillus は存在しないことを確認しておいた。

次の日に各群ラット口腔内に SM $100 \mathrm{mg} / \mathrm{ml}$ 耐性の ヤクルト菌を投与し， $\mathrm{A}$ 実験群は菌投与後二時間後, 四

\section{表 2 Rogosa SL 培地処方}

\begin{tabular}{lc}
\hline \hline Trypticase (BBL) & $10 \mathrm{~g}$ \\
Yeast ext (Difco) & $5 \mathrm{~g}$ \\
$\mathrm{KH}_{2} \mathrm{PO}_{4}$ & $6 \mathrm{~g}$ \\
Ammonium citrate $\left[\left(\mathrm{NH}_{4}\right)_{2} \mathrm{HC}_{6} \mathrm{H}_{5} \mathrm{O}_{7}\right]$ & $2 \mathrm{~g}$ \\
Salt solution & $5 \mathrm{ml}$ \\
Glucose & $20 \mathrm{~g}$ \\
Sorbitan monooleata & $1 \mathrm{~g}$ \\
Sodium acetate $\mathrm{NaC}_{2} \mathrm{H}_{3} \cdot 3 \mathrm{H}_{2} \mathrm{O}$ & $25 \mathrm{~g}$ \\
Glacial acetic acetic $(99.5 \%)$ & $1.32 \mathrm{ml}$ \\
Agar & $15 \mathrm{~g}$ \\
Distilled Water & $1.000 \mathrm{ml}$
\end{tabular}

$\mathrm{pH} 5.4$

Salts solution.

$\begin{array}{lc}\mathrm{Mg} \mathrm{SO}_{4} \cdot 7 \mathrm{H}_{2} \mathrm{O} & 11.5 \mathrm{~g} \\ \mathrm{MnSO}_{4} \cdot 2 \mathrm{H}_{2} \mathrm{O} & 2.4 \mathrm{~g} \\ \quad \text { or } \mathrm{MnSO}_{4} \cdot 4 \mathrm{H}_{2} \mathrm{O} & 2.86 \mathrm{~g} \\ \mathrm{Fe} \mathrm{SO} \cdot 7 \mathrm{H}_{2} \mathrm{O} & 0.68 \mathrm{~g} \\ \text { Distilled Woter } & 100 \mathrm{ml} .\end{array}$

時間後，八時間後，投与二日目から五日目までは一日一 回を午前九時に投与ヤクルト菌の検索を行なつた。B実 験群はヤクルト菌の投与を一日一回, 三日間, C実験群 はヤクルト菌の投与を一日一回，五日間行ない，投与終 了後にはA実験群と同様な方式で SM 耐性ヤクルト菌を 検索した。

表で明らかなように, 各実験群とも投与二時間後は非 常に多数ヤクルト菌が出現されるが時開の経過とともに 減少し, 二日目以後は各実験群とも, ヤクルト菌は全く 検出し得なかつた。これを図示したものが図 $1 ， 2 ， 3$ である。 
A 実験

表 3 生後三週間のラットにヤクルト菌を一日一回のみ投与せる後の本菌の消長

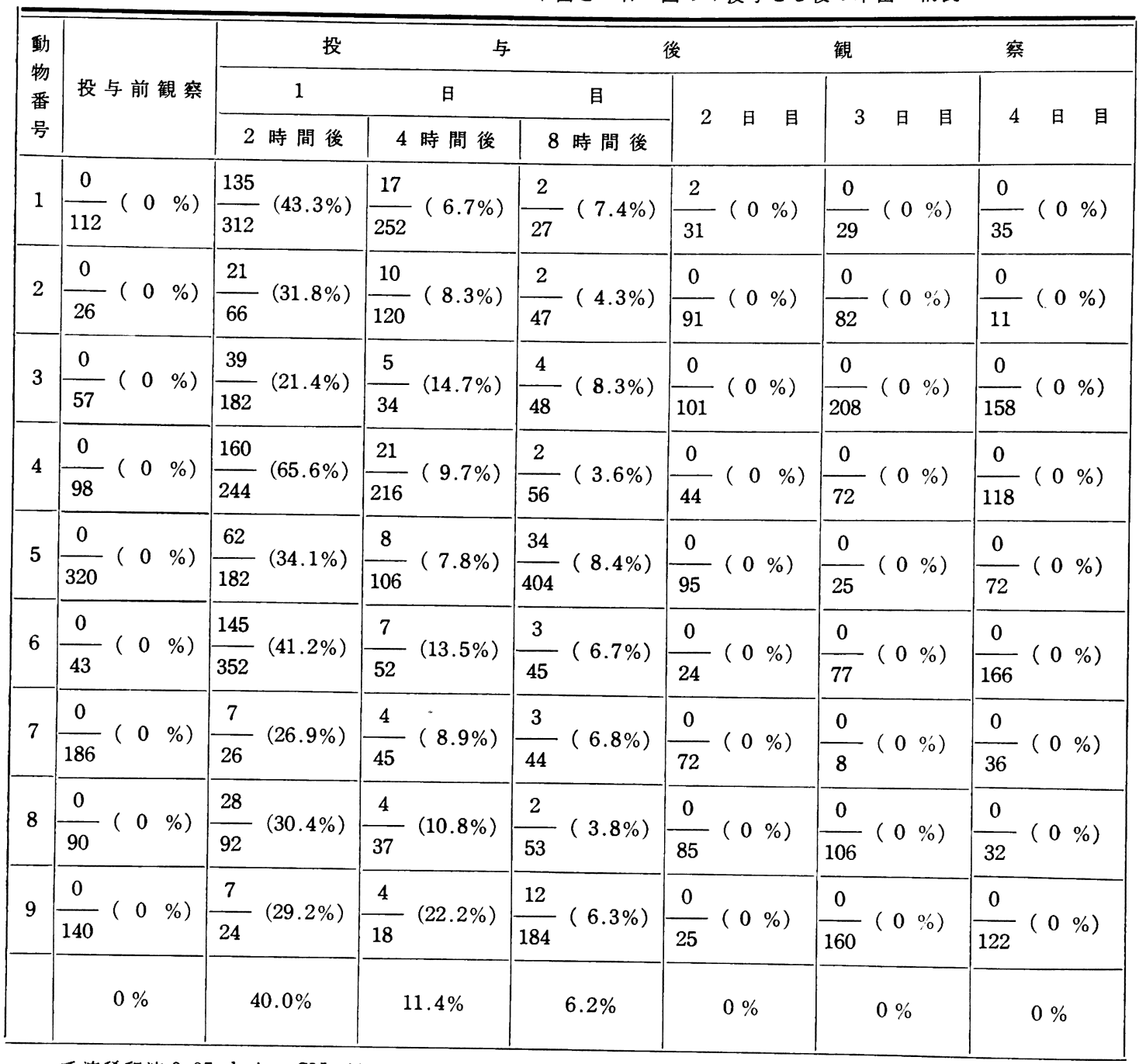

唾液稀䣋液 $0.05 \mathrm{ml}$ 中の $\mathrm{SN}$ 耐性ヤクルト菌数 
$\mathrm{B}$ 実験

表 4 生後三週間のラットにヤクルト菌を一日一回三日間連続投与せる後の本菌の消長

\begin{tabular}{|c|c|c|c|c|c|c|c|}
\hline \multirow{3}{*}{$\begin{array}{l}\text { 動 } \\
\text { 物 } \\
\text { 番 } \\
\text { 号 }\end{array}$} & \multirow{3}{*}{ 投与前観察 } & \multicolumn{2}{|l|}{ 投 } & \multicolumn{2}{|c|}{ 後 } & 観 & 察 \\
\hline & & 1 & 日 & 目 & & 日 & \multirow{2}{*}{ 目 } \\
\hline & & 2 時 間 後 & 4 時 間 後 & 8 時間 後 & & 日 & \\
\hline \multirow{2}{*}{11} & \multirow{2}{*}{$-(0 \%)$} & \multirow{2}{*}{$-(22.8 \%)$} & \multirow{2}{*}{$(8.1 \%)$} & \multirow{2}{*}{$-(3.6 \%)$} & \multirow{2}{*}{$-\left(\begin{array}{ll}0 & \%\end{array}\right)$} & \multirow{2}{*}{$\frac{0}{94}(0 \%)$} & \multirow{2}{*}{$-\left(\begin{array}{ll}0 \% \\
-\end{array}\right)$} \\
\hline & & & & & & & \\
\hline \multirow{2}{*}{12} & \multirow{2}{*}{$-(0 \%)$} & \multirow{2}{*}{$-(33.7 \%)$} & \multirow{2}{*}{$-(13.6 \%)$} & \multirow{2}{*}{$-(4.6 \%)$} & \multirow{2}{*}{$-\left(\begin{array}{ll}0 & \%\end{array}\right)$} & \multirow{2}{*}{$\frac{0}{106}(0 \%)$} & \multirow{2}{*}{$-\left(\begin{array}{ll}0 \% \\
-1\end{array}\right)$} \\
\hline & & & & & & & \\
\hline \multirow{2}{*}{13} & \multirow{2}{*}{$-\left(\begin{array}{ll}0 & \%\end{array}\right)$} & \multirow{2}{*}{$(37.9 \%)$} & 3 & 2 & 0 & 0 & 0 \\
\hline & & & $34(0.0 \%)$ & 65 & 74 & 102 & 434 \\
\hline Y & $(0 \Omega)$ & 6 & 7 & 3 & 0 & 0 & 0 \\
\hline & 258 & 27 & 51 & 80 & 53 & 72 & 100 \\
\hline 15 & 0 & 15 & $(1070)$ & 1 & 0 & 0 & 0 \\
\hline & 19 & 62 & 28 & 34 & 132 & 30 & 12 \\
\hline 16 & 0 & 38 & 9 & 1 & 0 & 0 & 0 \\
\hline & 45 & 119 & 75 & 29 & 40 & 41 & 75 \\
\hline 17 & 0 & $(257 \%)$ & 7 & 5 & $0 \%$ & 0 & 0 \\
\hline & 98 & 35 & 56 & 131 & 84 & 20 & 90 \\
\hline 18 & $\left(\begin{array}{ll}0 & 0\end{array}\right)$ & 7 & 10 & 4 & 0 & 0 & 0 \\
\hline & 72 & 33 & 88 & 94 & 150 . & 43 & 230 \\
\hline $10+2>$ & 0 & 14 & 10 & 2 & 0 & 0 & 0 \\
\hline 10 & (6) & 34 & 72 & 63 & 112 & 29 & 74 \\
\hline & $0 \%$ & $24.4 \%$ & $11.5 \%$ & $3.6 \%$ & $0 \%$ & $0 \%$ & $0 \%$ \\
\hline
\end{tabular}

唾液稀釈液 $0.05 \mathrm{ml}$ 中の $\mathrm{SM}$ 耐性ヤクルト菌数 
C 実験

表 5 生後三週間のラットにヤクルト菌を一日一回五日間連続投与せる後の本菌の消長

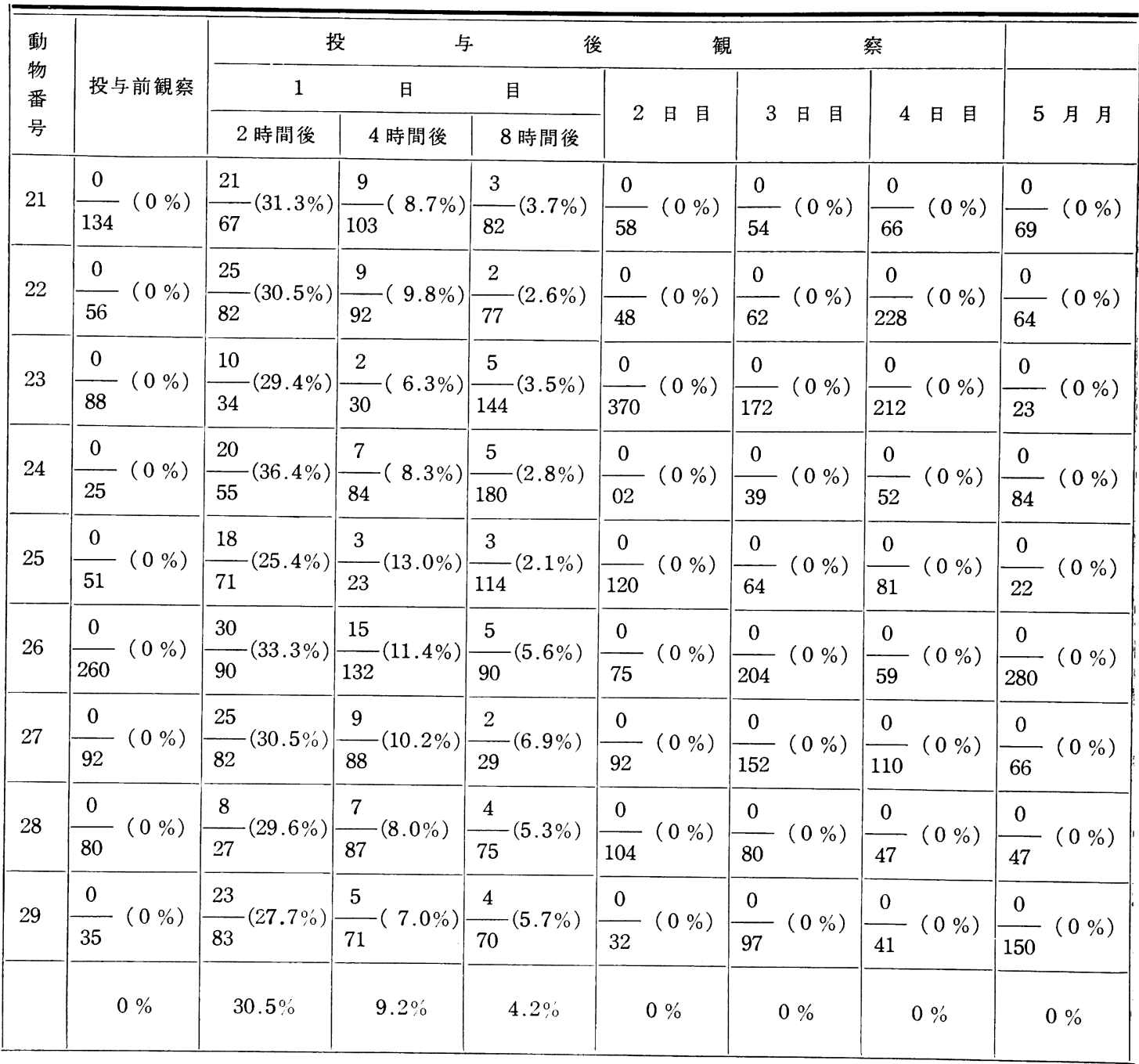

唾液稀釈液 $0.05 \mathrm{ml}$ 中の $\mathrm{SM}$ 耐性ヤクルト菌数 

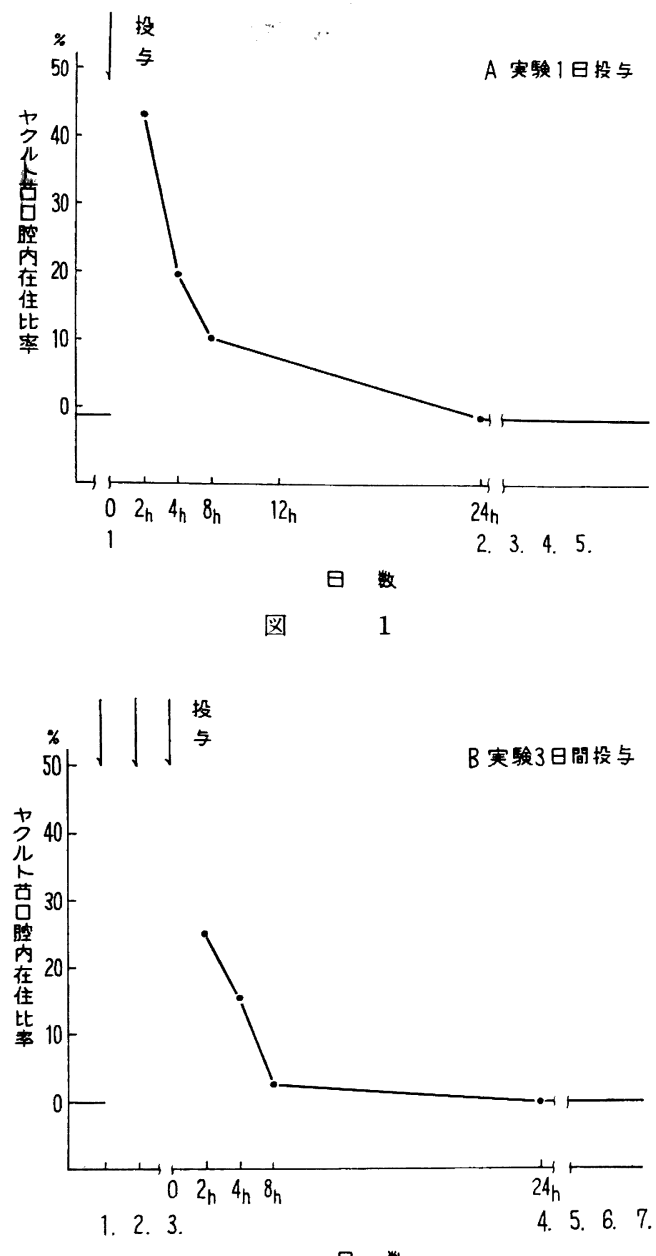

日 数

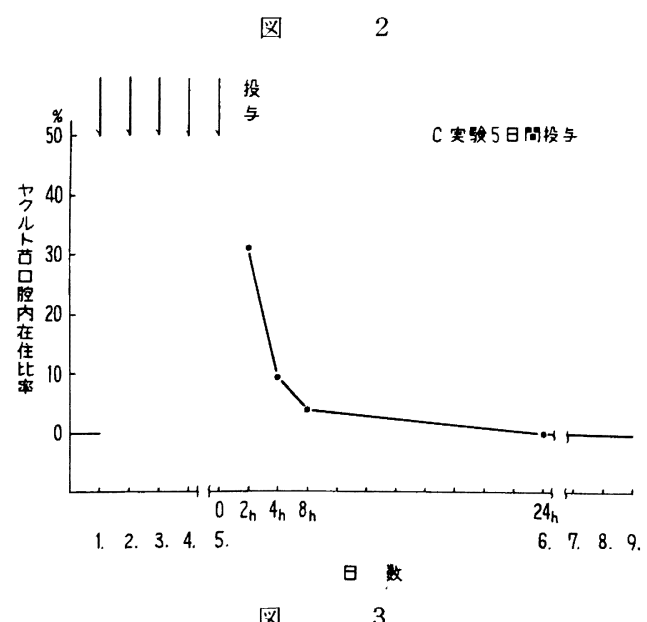

\section{IV. 考察}

ヒト歯牙唃蝕症の原因菌として Lactobacillus が重要 視されている現在, Lactobacillus の一菌種であるヤク ルト菌が唃蝕䍜患率の高い幼児, 児童〜毎日乳酸菌飲料 として, 飲料されていることは, 緒論に述べた理由で検 討されねばならないことである。そこで，ヒトとラット とでは同一視することは勿論できないのであるが, ひと まず実験動物ラットを使用し，ヤクルト菌のラット口腔 内投与の実験をその実験の結果, 投与した SM $100 \mathrm{mg} / \mathrm{ml}$ 耐性ヤクルト菌は，24時間以後にはすでに出現せず，消 失している事を認めた。その後, 約一力月間にわたり, 投与ヤクルト菌の口腔内出現の有無を追跡したのである がついにこれを証明し得なかつた。

このことはマウス口腔内に種々の細菌を投与しても, マウスの口腔内よりすみやかに消失するという亀ケ谷の

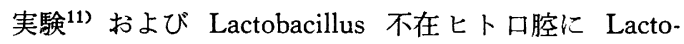
bacillus を投与しても本菌は定着しない。Lactobacillus 在住口腔でも，あとから投与した Lactobacillus が先住 Lactobacillus を追い出して自分が定着することができ ないといら住谷, 成沢 ${ }^{12} ら$ ら結果と全く同様であつた。 このことはヤクルトを飲料してもヤクルト菌が口腔内に 定着し, さらに増殖をつづけ, そのため䀞蝕の発症とい う直接的に関倸は今のところないであろうということを 示すものであろらと考えられる。しかし, 乳酸菌飲料が 数力月ないし，二年有余にわたつて毎日飲料される状態 は, 当人の口腔について Caries activity を考察する時 は，あたかも actiivty は陽性である状態におかれている のである。そのようなヒト口腔の状態について本小実験 をもつて, ただちに推察することは無理であるので人体 について，本実験を追求してみたいと思う。

\section{むすび}

幼若ラット口腔に, 腸内定着力が強いといわれるヤク ルト菌を投与しても, ヤクルト菌は口腔に定着さすこと ができず，ただちに消失することを認めた。

本研究の要旨は, 昭和 39 年第 1 回日本大学乳酸菌研究 会に掞いて発表した。

本研究の指遒をいただいた白土寿一教授に感謝し，な お本実験に協力してくれた教室員各位に謝意を表す。ま たいろいろと本実験に対しお力添えいただいたヤクルト 研究所に感謝する。 


\section{文献}

1）清水茂松・芝本源治：一株の好酸性乳酸菌（ヤ.ク ルト菌）が腸内ガス発生におよぼす影響の臨床的 観察, 東京医科大学雑誌, $21,6,1964$.

2) Bunting, R. W. : Studies on the relation of Bacillus acidophilus to dental caries (abst) J. D. Res. 8 : 222 April 1928.

3) Hemmes, E. S., Blayney, J. R., Bradel, S. F. and Harrisson, R. W. : The microbic flora of the dental plaque in relation to the beginning of caries J. D. Res. 25 : 195, Aug. 1946.

4) Rogosa's, M., Mitchell, J. A. and Wiseman,
R. F. : A selectine medium for the isolation and enumeration of oral Lactobacilli J. D. Res. 30, 682, 1951.

5）亀ケ谷義雄：口腔常在菌の常在機転に関する実験 的研究, 第 2 報, 試験動物「マウス」口腔に投与 せる細菌の口腔内消長について, 口腔衛生学会雑 誌, 1, 98, 1953.

6）住谷義雄 - 成沢龟一郎：酸好性乳酸桿菌 L. acidophilus の口腔内消長に関する研究，そのI，口 腔内投与 L. acidophilus の消長について, 口腔衛 生学会䧴誌, 8, 4, 1958.

7）代田 稔: ヤクルト菌について, 乳酸菌飲料文献 集， I， 1， 1963. 